\title{
Purification and Characterization of Antithrombotics from Syzygium aromaticum (L.) Merr. \& Perry
}

\author{
Jong Im Lee, ${ }^{a}$ Hyun Sun Lee, ${ }^{b}$ Woo Jin Jun, ${ }^{a}$ Kwang Won Yu, ${ }^{a}$ Dong Hoon Shin, ${ }^{a}$ \\ Bum Shik Hong, ${ }^{*, a}$ Hong Yon CHO, ${ }^{a}$ and Han Chul Y $\mathrm{ANG}^{a}$ \\ Graduate School of Biotechnology, Korea University, ${ }^{a}$ \#1, 5-Ka, Anam-Dong, Sungbuk-Ku, Seoul 136-701, Korea and \\ Institute of Biotechnology, Korea University, ${ }^{b}$ \#1, 5-Ka, Anam-Dong, Sungbuk-Ku, Seoul 136-701, Korea. \\ Received July 28, 2000; accepted November 21, 2000
}

\begin{abstract}
Two antithrombotic polysaccharides with relatively high molecular weight (HMW) and low molecular weight (LMW) were isolated from the flower buds of Syzygium aromaticum (L.) MErr. \& PERrY (clove) by anionexchange chromatography, hydrophobic interaction column chromatography and size exclusion chromatography (LMW: EC-2B-IIIa-2, M.W. ca. 34000; HMW: EC-2C-Ia-2, M.W. ca. 103000). The LMW polysaccharide was mainly composed of Rha, Gal, GalA and Ara (molar \%: 24.1, 18.9, 18.0 and 17.9, respectively) with $10.8 \%$ of sulfate and $18.2 \%$ of protein. The HMW fraction consisted of Ara, Gal, Glc and Rha (molar \%: 26.0, 23.7, 17.5 and 12.4 , respectively) with $15.4 \%$ of sulfate and $8.0 \%$ of protein. Both polysaccharides had the backbone of type I rhamnogalacturonan and the side chain of arabinan. Also, most of the sulfates were attached at the position 6 of 3-linked galactosyl residues. Compared to the antithrombotic activity of the HMW fraction (plasma clotting time of $145 \mathrm{~s}$ in APTT assay), the LMW fraction displayed a slightly low activity (90 s). However, animal studies indicated that crude $L M W$ polysaccharide did not show acute toxicity, while the acute $\mathrm{LD}_{50}$ of the $\mathrm{HMW}$ fraction was approximately 2 -fold lower than that of heparin.
\end{abstract}

Key words Syzygium aromaticum (L.) MERr. \& PERry; antithrombotics; pectic polysaccharide; type I rhamnogalacturonan

In the past several years, extensive investigations on searching for therapeutic agents have been made for the production of effective antithrombotics. Sulfated polysaccharides, a complex group of macromolecules, have been known to possess the antithrombotic activity. ${ }^{1}$ The anticoagulant glycosaminoglycan heparin is the initial-choice for the treatment and prevention of thrombotic diseases. ${ }^{2}$ Polysulfated pentosan, which is a chemically modified xylan sulfate, has been shown to exhibit antithrombotic activity for several years. ${ }^{3)}$ Mammalian dermatan sulfate is a specific known inhibitor of thrombin by heparin cofactor II activity. ${ }^{4)}$ The function of sulfated fucans from brown seaweed includes the inhibition of thrombin by antithrombin III or heparin cofactor II. ${ }^{5)}$ So far, the studies for the potential antithrombotics from natural sources have focused mostly on mammalian tissues and seaweeds. ${ }^{6}$ Recently, pharmaceutical function to certain ailments in edible plants has received an increasing attention. Therefore, it is necessary to evaluate the pharmaceutical action on the regulation systems of thrombosis by edible plants and identify their active components.

In the preliminary work, we screened 80 edible plants to examine the antithrombotic activities of their extracts. ${ }^{7)} \mathrm{A}$ relatively high activity was observed in the flower buds of Syzygium aromaticum (L.) Merr. \& Perry (clove). Thus, in the present study, we extracted and purified the antithrombotic polysaccharides from cloves. Also, the structural characteristics of purified antithrombotic polysaccharides were analyzed and compared.

\section{MATERIALS AND METHODS}

Materials Syzygium aromaticum (L.) MerR. \& PerRY (clove) cultivated in Holland was purchased from Hyangwon Spice Co. (Seoul, Korea), and was authenticated by Dr. SangIn Shim at Seed Bank for Wild Herbaceous Plant Species, Korea University. The voucher specimen was deposited at the same institute. Activated partial thromboplastin time (APTT) and thrombin time (TT) reagents were obtained from Dade Behring Inc. (New York, DE, U.S.A.). The 4th International Standard heparin (porcine mucosal heparin, 147 units $/ \mathrm{mg}$ ) was purchased from Sigma Chemical Co. (St. Louis, MO, U.S.A.). Resins of Butyl-Toyopearl 650M, Sephadex G-75, Sephadex G-100 and Sepharose CL-6B were purchased from Pharmacia Ltd. (Uppsala, Sweden), and DEAE-Toyopearl 650C from Tosoh Co. (Tokyo, Japan). Sep-Pak $\mathrm{C}_{18}$ cartridge was from Waters Associates (Milford, MA, U.S.A.). $\beta$-D-Glucosyl Yariv antigen was obtained from Biosupplies Australia (Parkville, Australia). All other chemicals were analytical reagent-grade.

Extraction Procedure Cloves $(1600 \mathrm{~g})$ were extracted five times with a total of 201 of methanol at room temperature. After filtration, the residue was re-extracted twice with $1.0 \mathrm{M} \mathrm{NaOH}$ at $70^{\circ} \mathrm{C}$ for $2 \mathrm{~h}$ to obtain an alkali extract (EC0 ). The extract was precipitated in $80 \%$ ethanol (EC-1), partially purified by $8 \%$ cetyltrimethylammonium bromide (EC2), and ultrafiltered with a $10 \mathrm{kDa}$ cellulose cartridge (Millipore Co., Bedford, MA, U.S.A.). The permeate was freezedried (EC-2A); the remnant was re-ultrafiltered with a $100 \mathrm{kDa}$ cellulose cartridge, and both permeate (EC-2B) and remnant (EC-2C) were freeze-dried to prepare crude antithrombotic polysaccharides (Fig. 1).

Purification Procedure For the purification of extractives, sequential column chromatography steps were carried out with both crude polysaccharides. Fractions with high antithrombotic activities were repeatedly subfractionated.

The EC-2B $(800 \mathrm{mg})$ was passed through a DEAE-Toyopearl $650 \mathrm{C}^{-}\left(\mathrm{Cl}^{-}\right)$column $(5 \times 45 \mathrm{~cm})$ eluted with 11 of distilled water and the successive stepwise gradient of $\mathrm{NaCl}$ $(0.5,1.0,1.5$ and $2.0 \mathrm{M})$. Each fraction was collected, dialyzed against tap water, and freeze-dried. The active fraction EC-2B-III $(500 \mathrm{mg})$, eluted with $1.0 \mathrm{~m} \mathrm{NaCl}$ was further purified by hydrophobic interaction column chromatography on 


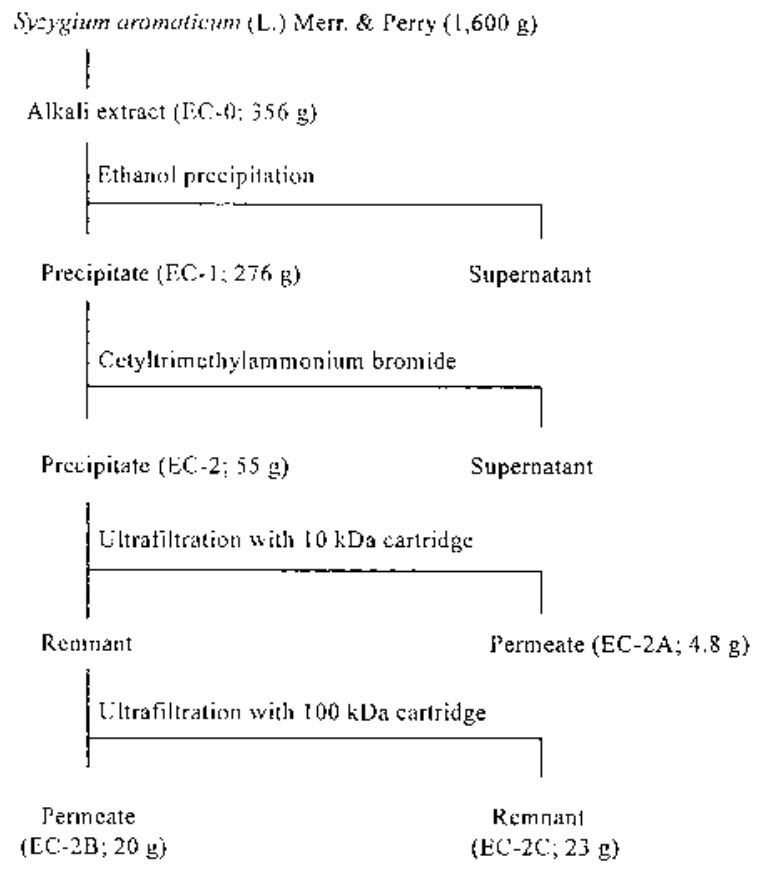

Fig. 1. Extraction of Antithrombotic Polysaccharides from Syzygium aromaticum (L.) MerR. \& PerRY

Butyl-Toyopearl $650 \mathrm{M}(4 \times 28 \mathrm{~cm})$ in $2 \mathrm{M} \mathrm{NaCl}$, followed by a linear water gradient $(2$ to $0 \mathrm{M} \mathrm{NaCl}$ ). Then, $25 \mathrm{mg}$ of unbound fraction (EC-2B-IIIa) was applied to a Sephadex G-75 gel column $(1.8 \times 93 \mathrm{~cm})$ using $0.2 \mathrm{M} \mathrm{NaCl}$ as an eluent. An active antithrombotic fraction (EC-2B-IIIa-2) was gathered, dialyzed and freeze-dried.

To purify EC-2C, $500 \mathrm{mg}$ of EC-2C was added onto a Butyl-Toyopearl $650 \mathrm{M}$ column $(4 \times 28 \mathrm{~cm})$, yielding two fractions with the same elution conditions as described above. The unbound fraction (EC-2C-I; $50 \mathrm{mg}$ ) was passed through a Sephadex G-100 gel column $(1.8 \times 93 \mathrm{~cm})$ with $0.2 \mathrm{M} \mathrm{NaCl}$ as an eluent. The active subfraction (EC-2C-Ia; $30 \mathrm{mg}$ ) eluted in a void volume was further separated on a Sepharose CL-6B column $(2.3 \times 94 \mathrm{~cm})$ using $0.2 \mathrm{M} \mathrm{NaCl}$ as an eluent, resulting in a purified antithrombotic polysaccharide (EC-2C-Ia-2).

General Methods Carbohydrate, uronic acid and protein contents were measured by the methods of phenol-sulfuric acid, ${ }^{8)} m$-hydroxydiphenyl ${ }^{9)}$ and Lowry, ${ }^{10)}$ respectively. Sulfate level was determined as described by Dodgson and Price. ${ }^{11)}$ Pronase digestion and periodate oxidation of the sample were performed according to the method of Yamada et al. ${ }^{12)}$ The HPLC analysis was carried out on a Waters 2690 (Milford, MA, U.S.A.) using a refractive index detector and a Shodex KB-805 column (Showa Denko K.K., Tokyo, Japan) eluted with $0.2 \mathrm{M} \mathrm{NaCl}$. The apparent molecular weight of the polysaccharide was measured by HPLC with standard markers. Single radical gel diffusion using a $\beta$-D-glucosylYariv antigen was conducted by the procedure of Holst and Clarke, ${ }^{13)}$ with acacia gum as a standard. The IR were recorded with $\mathrm{KBr}$ pellets in an infrared spectrophotometer (Bomen Michelson series MB 102-C15).

Analysis of Sugar Composition The sugar composition of polysaccharide was determined by GC as alditol acetate derivatives. ${ }^{14)}$ The GC analysis was carried out with a YoungLin 600D gas chromatograph (Young-Lin, Seoul, Korea) fit- ted with a flame-ionization detector. A SP-2380 capillary column $(30 \mathrm{~m} \times 0.25 \mathrm{~mm}$ i.d., $0.25 \mu \mathrm{m}$ film thickness; Supelco Inc.) was used. GC conditions were: injector temperature, $250^{\circ} \mathrm{C}$; splitless mode; carrier gas, $\mathrm{N}_{2}$; column temperature, $60^{\circ} \mathrm{C}$ for $1 \mathrm{~min}, 60 \rightarrow 220^{\circ} \mathrm{C}$ at $30^{\circ} \mathrm{C} / \mathrm{min}$, held for $12 \mathrm{~min}, 220 \rightarrow 250^{\circ} \mathrm{C}$ at $8^{\circ} \mathrm{C} / \mathrm{min}$ and held for $15 \mathrm{~min}$; and detector temperature, $250^{\circ} \mathrm{C}$. The molar percentages of neutral sugars and uronic acids were calculated from the peak areas.

Methylation Analysis For structural analysis, the polysaccharide was methylated with sodium methyl sulfinyl carbanion and methyl iodide in dimethylsulfoxide. ${ }^{15)}$ Uronic acids in the methylated polysaccharide were reduced by $1 \mathrm{ml}$ of $\mathrm{LiB}\left(\mathrm{C}_{2} \mathrm{H}_{5}\right)_{3} \mathrm{D}$ in trifluoroacetic acid (TFA) (Super-Deuteride $^{\circledR}$, Sigma Co.) for $1 \mathrm{~h}$ at room temperature, and then purified using a Sep-Pak $\mathrm{C}_{18}$ cartridge. ${ }^{16)}$ The partially $O$ methylated alditol acetate derivatives were analyzed with a HP 6890/HP 5792A GC automated mass spectrometer system (Hewlett-Packard Co., Avandale, PA, U.S.A.), using a splitless injector and a SP-2380 capillary column $(30 \mathrm{~m} \times$ $0.25 \mathrm{~mm}$ i.d., $0.25 \mu \mathrm{m}$ film thickness; Supelco Inc.). The column temperature was programmed as follows; $60^{\circ} \mathrm{C}$ for $1 \mathrm{~min}, 60 \rightarrow 150^{\circ} \mathrm{C}$ at $30^{\circ} \mathrm{C} / \mathrm{min}, 150 \rightarrow 250^{\circ} \mathrm{C}$ at $1.5^{\circ} \mathrm{C} / \mathrm{min}$, and held for $5 \mathrm{~min}$. The peaks were identified by comparison of retention time of 2,3,4,6-tetra-O-methyl galactitol acetate and fragmentation patterns.

Determination of Sulfate Location in Polysaccharide The methylated polysaccharide was methanolyzed in $91 \mathrm{~mm}$ methanol- $\mathrm{HCl}$ for $24 \mathrm{~h}$ at room temperature. After the methanolyzate was dried, it was re-methylated with $\mathrm{CD}_{3} \mathrm{I}$ and hydrolyzed with $1 \mathrm{~m}$ TFA for $1 \mathrm{~h}$ at room temperature. ${ }^{17)}$ The hydrolyzate was converted into its corresponding alditol acetates as previously described. ${ }^{15)}$ The alditol acetate derivatives were analyzed in a GC-MS unit.

Clotting Assay The APTT and TT were measured at $37^{\circ} \mathrm{C}$ with use of an automatic blood coagulater (Clot-1A; Hospitex Dianostics, Milan, Italy) as described by Hara et al. ${ }^{18)}$ Briefly, a sample dissolving in $100 \mu$ of human citrated platelet-poor plasma $(1: 10 \mathrm{v} / \mathrm{v}, 3.8 \%$ sodium citrate $)$ was warmed at $37^{\circ} \mathrm{C}$, and then $100 \mu \mathrm{l}$ of prewarmed APTT reagent was added. The mixture was incubated at $37^{\circ} \mathrm{C}$ for 180 s. A $100 \mu \mathrm{l}$ of prewarmed $20 \mathrm{~mm} \mathrm{CaCl}_{2}$ was then added and APTT was recorded as the time for clot formation to occur. The TT was determined by the same method as APTT, except for TT reagent and no addition of $\mathrm{CaCl}_{2}$.

In Vivo Acute Toxicity of Sample Male ICR mice $(25-30 \mathrm{~g})$ were purchased from Sam-Yook Animal Co. (Osan, Korea) and acclimatized for 1 week at a temperature of $24 \pm 1^{\circ} \mathrm{C}$ with free access to a commercial pellet diet purchased from Samyang Co. (Wonju, Korea). The sample to be tested was intravenously injected into the tail veins of mice at various doses. The mortality of mice was recorded for $24 \mathrm{~h}$. In each experimental session, ten animals per treated group were tested.

Statistical Analysis Data were analyzed by the difference between means, and statistical significance was calculated from Fisher's least significant difference (LSD) or Student's $t$-test. 


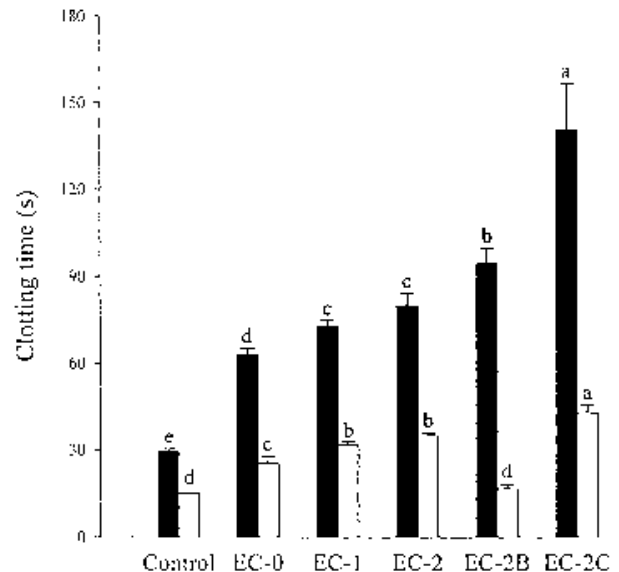

Fig. 2. Antithrombotic Activities of Fractions from Syzygium aromaticum (L.) Merr. \& Perry

Each sample at the concentration of $100 \mu \mathrm{g} / \mathrm{ml}$ was assayed by APTT ( $\square$ ) and TT ( $\square$ ) prolongations. Values represent the mean \pm S.D. of three replicates. Different letters above the columns in each assay are statistically different by the analysis of Fisher's least significant difference $(p<0.01)$.

\section{RESULTS}

Isolation of Antithrombotic Polysaccharides from the Flower Buds of Syzygium aromaticum (L.) Merr. \& Perry Two crude macromolecules were separated from cloves by alkali extraction, ethanol precipitation, cetyltrimethylammonium bromide treatment, and ultrafiltration; one (EC-2B) was less than $100 \mathrm{kDa}$ but greater than $10 \mathrm{kDa}$ in size, and the other (EC-2C) was greater than $100 \mathrm{kDa}$ (Fig. 1). The prolonged clotting time in the APTT assay was observed in both EC-2B and $-2 \mathrm{C}$, while only EC-2C for the prolonged TT (Fig. 2). The antithrombotic activities of EC-2B and -2C, treated with pronase did not significantly change. However, a dramatic decrease in activity was found after oxidized with periodate (data not shown). These results indicate that the major part of these macromolecules with antithrombotic activity appears to be polysaccharides.

The DEAE-Toyopearl 650C-purified antithrombotic polysaccharide (EC-2B-III) was eluted at $1.0 \mathrm{M}$ of salt concentration (Fig. 3A). On Butyl-Toyopearl 650M chromatography which separates the substances by hydrophobic characteristics, the unbound fraction containing mainly the sugar of EC2B-IIIa was obtained (Fig. 3B). Since EC-2B was fractionated by ultrafiltration with a less than $100 \mathrm{kDa}$, molecular sizing on Sephadex G-75 was chosen for the separation of highly purified antithrombotic polysaccharide. The EC-2BIIIa was divided into three subfractions (Fig. 3C). Of those, relatively high antithrombotic activity was found in subfraction with the elution volume from 122 to $186 \mathrm{ml}$ (EC-2BIIIa-2), as shown in Table 1. Like the case of EC-2B, the unbound fraction (EC-2C-I) of EC-2C on a Butyl-Toyopearl $650 \mathrm{M}$ column was high in sugar content compared to the hydrophobic fraction (Fig. 4A). The antithrombotic activities of EC-2C-I in both APTT and TT assays were noticeably higher than those of the hydrophobic fraction (Table 1). The hydrophilic fraction was further purified by the sequential size exclusion chromatographies on the Sephadex G-100 and Sepharose CL-6B columns (Figs. 4B and C). Among three subfractions obtained by the Sepharose CL-6B column chromatography, the intermediate molecular-mass fraction (EC-

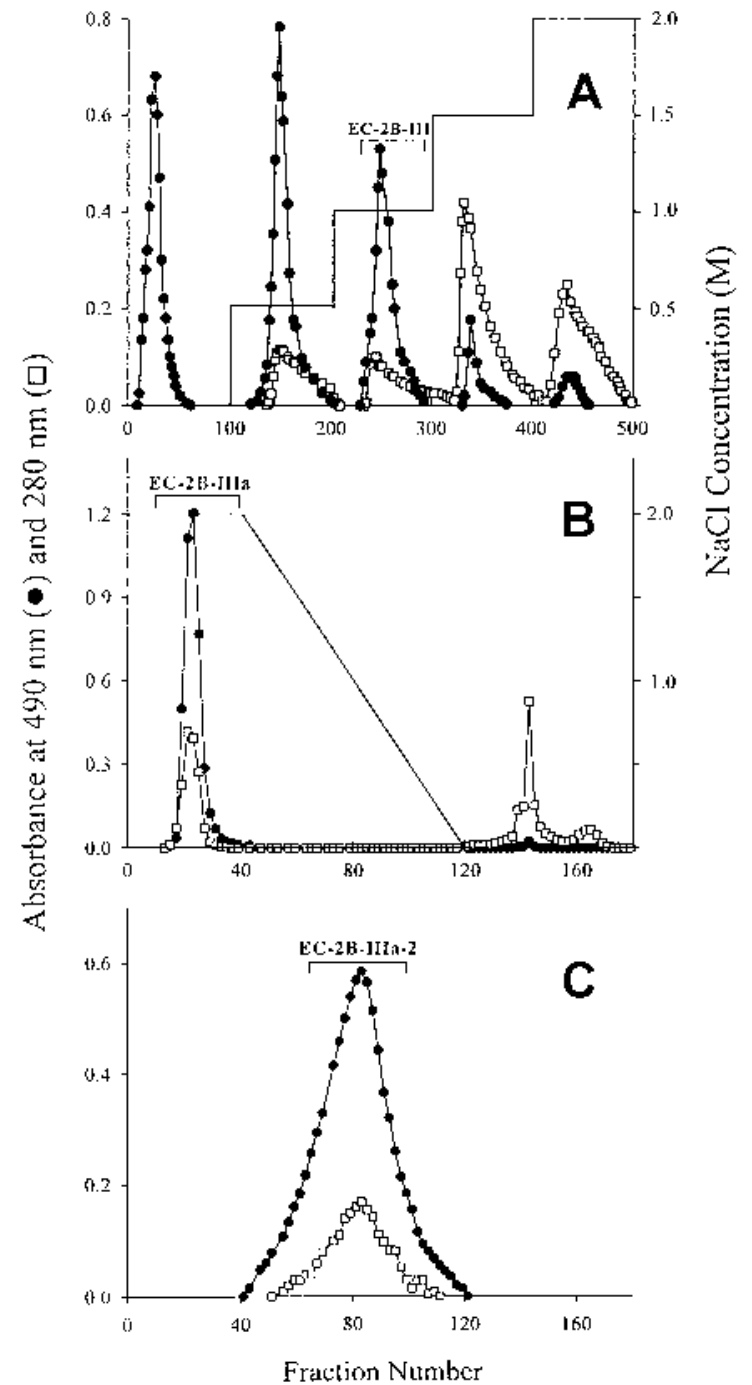

Fig. 3. Purification of the Low Molecular-Weight Antithrombotic Polysaccharide from Syzygium aromaticum (L.) MERr. \& PERRY by DEAEToyopearl 650C (A), Butyl-Toyopearl 650M (B) and Sephadex G-75 (C)

Fractions were checked at $490 \mathrm{~nm}$ for total sugar $(\bullet)$ by the phenol- $\mathrm{H}_{2} \mathrm{SO}_{4}$ reaction and at $280 \mathrm{~nm}$ for protein $(\square)$. Fraction size and flow rate of each column chromatography were i) A: $10 \mathrm{ml} /$ tube and $1 \mathrm{ml} / \mathrm{min}$; ii) B: $5 \mathrm{ml} /$ tube and $1 \mathrm{ml} / \mathrm{min}$; and iii) C: $2 \mathrm{ml} /$ tube and $0.3 \mathrm{ml} / \mathrm{min}$, respectively. Further details are described under Materials and Methods.

2C-Ia-2; Vol. $=104-150 \mathrm{ml}$ ) markedly increased the antithrombotic activities in vitro (Table 1). Compared to heparin, two purified polysaccharides, EC-2B-IIIa-2 and EC2C-Ia-2, possessed the slightly low inhibitory ability of thrombus formation. Both antithrombotic polysaccharides showed a single peak on HPLC, indicating that they were highly purified (Fig. 5).

Molecular Weights and Chemical Characteristics of Antithrombotic Polysaccharides The molecular weights of EC-2B-IIIa-2 and EC-2C-Ia-2 were determined to be 34000 and 103000 , respectively. The relatively high molecular-weighted (HMW) polysaccharide, EC-2C-Ia-2, was high in neutral sugar, whereas the low molecular-weighted (LMW) fraction, EC-2B-IIIa-2, contained a large amount of uronic acid (Table 2). The two purified polysaccharides displayed substantially different sugar compositions. The LMW polysaccharide mainly comprised $\mathrm{Rha}>\mathrm{Gal}>\mathrm{GalA}>\mathrm{Ara}$, while the major sugars in HMW fraction were Ara $>\mathrm{Gal}>$ 
Table 1. Antithrombitic Activities of Fractions from Syzygium aromaticum (L.) MERR. \& PerRY

\begin{tabular}{|c|c|c|c|c|}
\hline \multirow{2}{*}{ Fraction } & \multirow{2}{*}{$\begin{array}{c}\text { Antithrombotic activity } \\
\text { APTT (s) }\end{array}$} & \multirow{2}{*}{ Fraction } & \multicolumn{2}{|c|}{ Antithrombotic activity } \\
\hline & & & $\operatorname{APTT}(\mathrm{s})$ & TT (s) \\
\hline Control & $29.5 \pm 0.9$ & Control & $29.5 \pm 0.9$ & $15.0 \pm 0.3$ \\
\hline Heparin & $177.3 \pm 1.9 * *$ & Heparin & $177.3 \pm 1.9 * *$ & $40.3 \pm 0.2 * *$ \\
\hline DEAE-Toyopearl 650C & & Butyl-Toyopearl 650M & & \\
\hline EC-2B-I & $28.5 \pm 0.2$ & EC-2C-I & $88.1 \pm 6.5 * *$ & $31.1 \pm 2.6^{* *}$ \\
\hline EC-2B-II & $30.3 \pm 0.8$ & EC-2C-II & $43.2 \pm 3.0 * *$ & $14.9 \pm 0.4$ \\
\hline EC-2B-III & $47.1 \pm 2.1 * *$ & & & \\
\hline EC-2B-IV & $28.6 \pm 0.1$ & Sephadex G-100 & & \\
\hline EC-2B-V & $28.6 \pm 0.1$ & EC-2C-Ia & $135.7 \pm 9.1 * *$ & $35.6 \pm 2.0 * *$ \\
\hline Butyl-Toyopearl 650M & & $\mathrm{EC}-2 \mathrm{C}-\mathrm{Ib}$ & $78.6 \pm 2.6 * *$ & $21.0 \pm 3.4^{*}$ \\
\hline EC-2B-IIIa & $67.7 \pm 1.8 * *$ & EC-2C-Ic & $83.5 \pm 7.1 * *$ & $14.9 \pm 0.1$ \\
\hline EC-2B-IIIb & $46.5 \pm 1.9 * *$ & & & \\
\hline Sephadex G-75 & & Sepharose CL-6B & & \\
\hline EC-2B-IIIa-1 & $34.2 \pm 2.3 *$ & EC-2C-Ia-1 & $57.6 \pm 2.5 * *$ & $30.2 \pm 0.7 * *$ \\
\hline EC-2B-IIIa-2 & $90.3 \pm 3.0 * *$ & EC-2C-Ia-2 & $145.3 \pm 9.9 * *$ & $36.8 \pm 2.5 * *$ \\
\hline EC-2B-IIIa-3 & $38.9 \pm 4.5^{*}$ & EC-2C-Ia-3 & $33.1 \pm 1.6^{*}$ & $22.4 \pm 3.0^{*}$ \\
\hline
\end{tabular}

The activated partial thromboplastin time (APTT) and thrombin time (TT) were expressed as the time for clot formation to occur from the point of addition of CaCl ${ }_{2}$ and $\mathrm{TT}$ reagent, respectively. The concentrations of sample and heparin used were $25 \mu \mathrm{g} / \mathrm{ml}$ and $4 \mu \mathrm{g} / \mathrm{ml}$ for APTT assay, and $50 \mu \mathrm{g} / \mathrm{ml}$ and $8 \mu \mathrm{g} / \mathrm{ml}$ for TT assay, respectively. Values represent the mean \pm S.D. of three replicates. Statistical analysis was performed using a Student's $t$-test: $* p<0.05, * * p<0.01$ versus control.

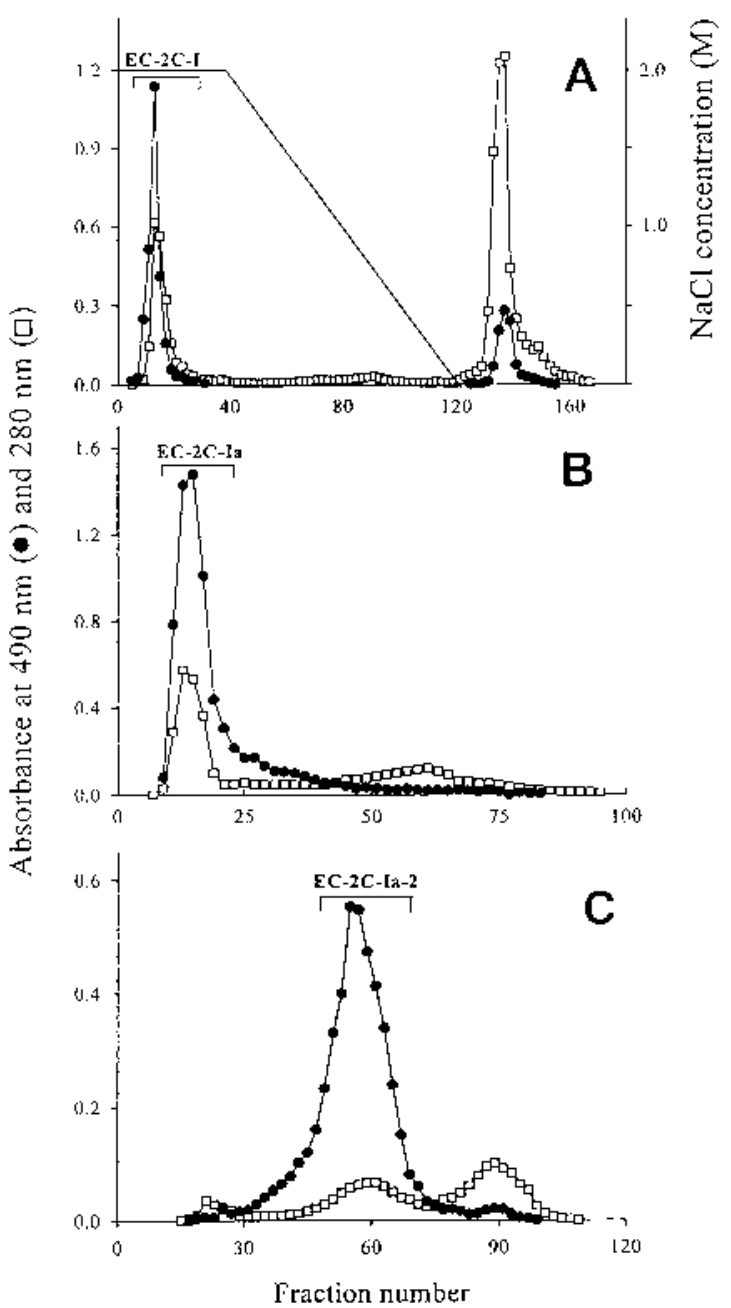

Fig. 4. Purification of the High Molecular-Weight Antithrombotic Polysaccharide from Syzygium aromaticum (L.) MERr. \& PERRY by Butyl-Toyopearl 650M (A), Sephadex G-100 (B) and Sepharose CL-6B (C)

Fractions were checked at $490 \mathrm{~nm}$ for total sugar $(-)$ by the phenol- $\mathrm{H}_{2} \mathrm{SO}_{4}$ reaction and at $280 \mathrm{~nm}$ for protein $(\square)$. Fraction size and flow rate of each column chromatography were i) A: $5.0 \mathrm{ml} /$ tube and $1 \mathrm{ml} / \mathrm{min}$; ii) B: $2.5 \mathrm{ml} /$ tube and $0.3 \mathrm{ml} / \mathrm{min}$; and iii) C: $2.2 \mathrm{ml} /$ tube and $0.2 \mathrm{ml} / \mathrm{min}$, respectively. Further details are described under Materials and Methods.
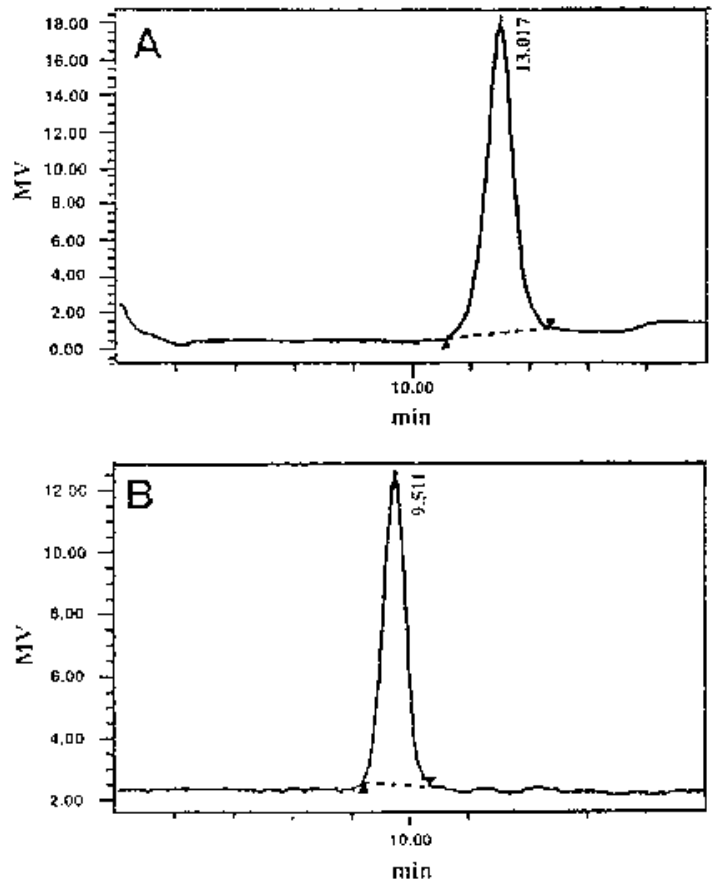

Fig. 5. HPLC Profiles of the Purified Low Molecular-Weight (A) and High Molecular-Weight (B) Antithrombotic Polysaccharides from Syzygium aromaticum (L.) MERR. \& PERRY

The HPLC analysis was performed on a Waters 2690 instrument, using a refractive index detector and a column $(8 \times 300 \mathrm{~mm})$ of Shodex KB- 805 . A $0.2 \mathrm{M}$ of $\mathrm{NaCl}$ was used as mobile phase with a flow rate of $0.7 \mathrm{ml} / \mathrm{min}$.

Glc $>$ Rha $>$ GalA. The sulfate contents were $10.8 \%$ for LMW polysaccharide, and $15.4 \%$ for HMW polysaccharide. On IR spectra, we could confirm the adsorption bonds with strong $\mathrm{S}=\mathrm{O}$ stretching vibration at $1240 \mathrm{~cm}^{-1}$ and adsorption bonds of $\mathrm{C}-\mathrm{O}-\mathrm{S}$ stretching vibration at $818 \mathrm{~cm}^{-1}$.

General Linkage Analysis of Antithrombotic Polysaccharides The results of methylation analysis are shown in Table 3. The GalA was mainly present as 4-linked residues in the LMW polysaccharide. Also, significant amounts of 2linked and 2,4-branched Rha were observed. In addition, 
Table 2. Molecular Weights and Chemical Characteristics of EC-2B-IIIa-2 and EC-2C-Ia-2 Obtained from Syzygium aromaticum (L.) Merr. \& Perry

\begin{tabular}{lcc}
\hline & EC-2B-IIIa-2 & EC-2C-Ia-2 \\
\hline Apparent molecular weight & 34000 & 103000 \\
Neutral sugar (\%) & 47.4 & 60.1 \\
Uronic acid (\%) & 18.1 & 10.4 \\
Protein (\%) & 18.2 & 8.0 \\
Sulfate (\%) & 10.8 & 15.4 \\
Sugar composition (molar \%) & & \\
Rha & 24.1 & 12.4 \\
Ara & 17.9 & 26.0 \\
Xyl & 4.3 & 3.6 \\
Gal & 18.9 & 23.7 \\
Glc & 9.5 & 17.5 \\
GalA & 18.0 & 11.7 \\
GlcA & 7.3 & 4.9 \\
IR (cm ${ }^{-1}$ ) & 818,1240 & 818,1240 \\
\hline
\end{tabular}

Table 3. Methylation Analysis of Anticoagulant Polysaccharides from Syzygium aromaticum (L.) MerR. \& PERrY

\begin{tabular}{|c|c|c|c|c|}
\hline \multirow{2}{*}{$\begin{array}{l}\text { Glycosyl } \\
\text { residue }\end{array}$} & \multirow{2}{*}{$\begin{array}{l}\text { Position of } \\
O \text {-Me group }\end{array}$} & \multirow{2}{*}{$\begin{array}{l}\text { Glycosidic } \\
\text { linkage }\end{array}$} & \multicolumn{2}{|c|}{ EC-2B-IIIa-2 EC-2C-Ia-2 } \\
\hline & & & Molar \% & Molar \% \\
\hline \multirow[t]{4}{*}{ Rha } & $2,3,4$ & (T)-Rha & 1.5 & 1.0 \\
\hline & 3,4 & 2-Rha & 11.8 & 6.3 \\
\hline & 3 & 2,4-Rha & 10.8 & 7.7 \\
\hline & 4 & 2,3-Rha & 2.6 & 1.3 \\
\hline \multirow[t]{5}{*}{ Ara } & $2,3,4$ & $(\mathrm{~T})-\operatorname{Ara}(\mathrm{p})$ & 2.4 & trace \\
\hline & $2,3,5$ & $(\mathrm{~T})-\operatorname{Ara}(\mathrm{f})$ & 4.8 & 6.7 \\
\hline & 2,3 & 4 or 5 -Ara & 2.4 & 4.4 \\
\hline & 2,4 & 3-Ara & 1.4 & 4.7 \\
\hline & 3,5 & 2-Ara & 1.8 & 2.7 \\
\hline \multirow[t]{2}{*}{$\mathrm{Xyl}$} & $2,3,4$ & (T)-Xyl(f) & 1.1 & 1.3 \\
\hline & 2,3 & 4 or $5-\mathrm{Xyl}$ & 3.9 & 2.6 \\
\hline \multirow[t]{6}{*}{ Gal } & $2,3,4,6$ & (T)-Gal & 4.4 & 3.3 \\
\hline & $2,3,4$ & 6-Gal & 4.0 & 2.3 \\
\hline & 2.4 .6 & 3-Gal & 4.8 & 9.0 \\
\hline & 2,3 & 4, 6-Gal & 2.3 & 2.1 \\
\hline & 2,4 & 3, 6-Gal & 1.9 & 6.1 \\
\hline & 2,4 & 6-Sulfated 3-Gal & 2.6 & 3.8 \\
\hline \multirow[t]{4}{*}{ Glc } & $2,3,4,6$ & (T)-Glc & 1.5 & 1.5 \\
\hline & $2,3,6$ & 4-Glc & 1.5 & 8.9 \\
\hline & $2,4,6$ & 3-Glc & 2.9 & 1.8 \\
\hline & 6 & 2, 3, 4-Glc & 2.4 & 5.0 \\
\hline \multirow[t]{2}{*}{ GalA } & 2,3 & 4-GalA & 14.1 & 11.5 \\
\hline & 2 & $3,4-\mathrm{GalA}$ & 4.0 & 1.5 \\
\hline \multirow[t]{2}{*}{ GlcA } & $2,3,4$ & (T)-GlcA & 4.9 & 2.4 \\
\hline & 2,3 & 4-GlcA & 3.1 & 1.9 \\
\hline
\end{tabular}

Terminal residues (T), furanosyl (f), and pyranosyl (p). Trace means less than 0.5 molar \%.

LMW polysaccharide contained appreciable amounts of terminal Ara(f) and 3-linked Gal residues. The major glycosidic linkages present in the HMW polysaccharide (EC-2C-Ia-2) were 4-linked GalA, 3-linked Gal, 4-linked Glc, 2,4branched Rha, 2-linked Rha, and terminal Ara(f). Unlike LMW polysaccharide, the occurrence of substantial amounts of 4-linked Glc residues was detected in the HMW polysaccharide, which implies that it contained significant amounts of cellulose. Also, relatively high amounts of 3- and 3,6linked Gal with terminal Ara(f) units were detected in this polysaccharide, resulting in a strong reactivity with the $\beta$-Dglucosyl-Yariv antigen on single radical gel diffusion (Fig. 6). The $\beta$-D-glucosyl-Yariv antigen has been known to selec-

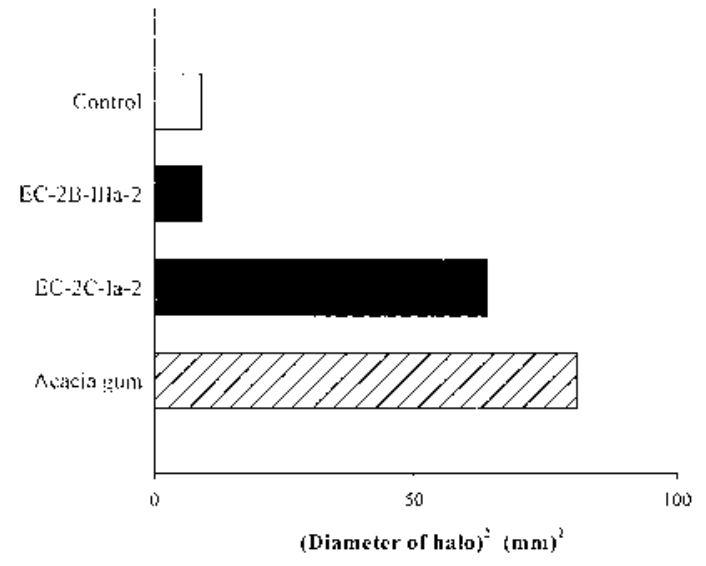

Fig. 6. Reactivities of the Purified Antithrombotic Polysaccharides to $\beta$-DGlucosyl-Yariv Antigen

Acacia gum (arabinogalactan) was used as a reference.

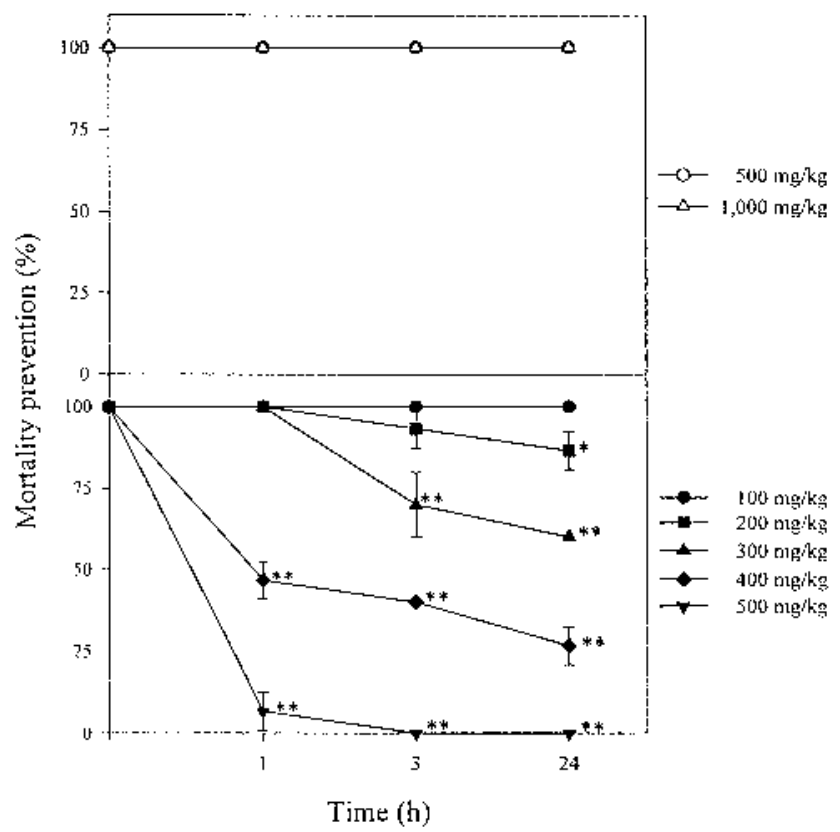

Fig. 7. In Vivo Acute Toxicities of the Crude Low Molecular-Weight (A) and High Molecular-Weight (B) Antithrombotic Polysaccharides

The sample was intravenously injected into the tail veins of mice. Mortality prevention was expressed as the percentage of the No. of alive mice to the No. of all tested mice. Each point represents the mean \pm S.D. of 10 animals. Statistical analysis was performed using a Student's $t$-test: $* p<0.05, * * p<0.01$ versus control.

tively react with arabiongalactan residues.

The methylated polysaccharides were re-methylated into $\mathrm{CD}_{3}$ I to substitute the $O$-sulfated position with the $O$-deuteriomethylated group. Obviously, the $O$-deuteriomethylated groups of both antithrombotic polysaccharides were found at the position 6 of 3-linked Gal residues (Table 3). Compared to the HMW polysaccharide, a slightly elevated level of 6-Osulfation was found in the LMW polysaccharide, which is in general agreement with the results of total sulfate contents of the two antithrombotic polysaccharides, as shown in Table 2.

In Vivo Acute Toxicities of Crude Antithrombotic Polysaccharides The acute toxic effects of crude LMW (EC2B) and HMW (EC-2C) antithrombotic polysaccharides were studied in the normal mice. The changes in mortality caused by five different doses of the crude HMW polysaccharide are 
shown in Fig. 7B. No significant toxicity was found up to the dose of $100 \mathrm{mg} / \mathrm{kg}$, but the mortality was drastically increased with an elevation in dosage. At the dose of $500 \mathrm{mg} /$ $\mathrm{kg}, 90 \%$ mortality was exhibited within an hour. Compared to the literature $\mathrm{LD}_{50}$ value of heparin $(750 \mathrm{mg} / \mathrm{kg})$, this polysaccharide might be relatively toxic with $322 \mathrm{mg} / \mathrm{kg}$ of an acute $\mathrm{LD}_{50}{ }^{19)}$ In contrast, no mortality of mice was observed up to $1000 \mathrm{mg} / \mathrm{kg}$ of crude LMW polysaccharide injected intravenously into the tail veins, indicating that it does not exhibit acute toxicity.

\section{DISCUSSION}

Sulfated polysaccharides, especially from seaweeds have been identified as the potential source of antithrombotic products. ${ }^{3,5,6)}$ However, only a few studies on the polysaccharides from plants have been reported regarding antithrombotic activity. ${ }^{20)}$ In the present study, we isolated two sulfated polysaccharides with a comparable antithrombotic activity from Syzygium aromaticum (L.) MERr. \& PERrY (clove), one of the species, by using an ultrafiltration membrane with a molecular weight cut-off of $100 \mathrm{kDa}$. In the course of purification, we employed the Butyl-Toyopearl 650M chromatography. This application has often been used to eliminate the impurities from proteins due to the hydrophobic characteristics of resin. In our case, it could be useful to separate the polysaccharide-rich fraction from the protein-rich one. Note that the sulfated polysaccharide from cloves shows a slightly lower salt concentration $(c a .1 .0 \mathrm{M})$ necessary for elution from the ion-exchange column than algal sulfated polysaccharide $\left.(c a .1 .5 \mathrm{M}) .^{21}\right)$ This can be, at least in part, explained by the relatively low sulfate/sugar ratio in the clove-based polysaccharides. Based upon the results, it would be assumed that the polysaccharide from cloves has distinctive structural characteristics compared to algal polysaccharide.

The antithrombotic action of the two purified polysaccharides from cloves appears to be different. Usually, antithrombotic action is mediated by plasma protease inhibitors. Thus, antithrombin III is a major regulator of heparin for inhibiting thrombin, factor Xa, and/or other coagulation enzymes. ${ }^{2)}$ For the inhibition of thrombin, heparin must complex with both antithrombin III and thrombin. However, it inactivates factor $\mathrm{Xa}$ without directly binding to factor Xa. Therefore, a longer chain of saccharides is required to inhibit the thrombin. ${ }^{22}$ The comparison data between heparin and low molecularweight heparin in the APTT and TT assays shows that heparin has the prolonged clotting time in both assays. ${ }^{22)}$ On the other hand, the prolonged clotting time in only the APTT assay is observed with the low molecular-weight heparin. Based on these facts, we presumed that the action mode of LMW polysaccharide from cloves is likely to be a low molecular-weight heparin type, and that of HMW polysaccharide may be a heparin type. The ATPP is widely used to monitor the therapeutic level of heparin-induced anticoagulation. Although both HMW and LMW polysaccharides from cloves apparently have an antithrombotic ability, their activities in vitro are lower than that of heparin. However, it should be pointed out that the comparison with heparin in single antithrombotic parameter does not entirely explain all the efficacy of antithrombotic agents.

Methylation analysis of the two antithrombotic polysac- charides indicates that these polymers have complex and heterogeneous structures. Nonetheless, some structural features can be deduced from these analyses. Both antithrombotic polysaccharides were rich in pectic polysaccharides as can be inferred from the occurrence of variously linked rhamnosyl, galactosyl, and arabinosyl residues. ${ }^{23)}$ As most of the uronic acid was shown to be GalA, very high amounts of rhamnogalacturonan were likely to be present. Noticeably, significant amounts of 4-linked Glc residues in the HMW fraction suggest the existence of appreciable cellulose. On the IR spectra, we detected the IR absorption bands at $818 \mathrm{~cm}^{-1}$. According to the work by Perlin and Casu, ${ }^{24)}$ the IR absorption bands at $900-800 \mathrm{~cm}^{-1}$ occurred due to $\mathrm{C}-\mathrm{O}-\mathrm{S}$ stretching vibration by sulfated polysaccharides. The sulfates in both polysaccharides were located at position 6 on the 3-linked Gal. These are in agreement with the report by Nishino et al., ${ }^{25)}$ who found that the absorption bands at $820 \mathrm{~cm}^{-1}$ were caused by 6-sulfated-D-Gal. Overall, the structures of both LMW and HMW polysaccharides are inferred to have the backbone of type I rhamnogalacturonan with repeated units of 4-linked GalA, 2-linked Rha and a side chain of 2,4branched Rha with arabinan or galactan on the 4 position. In addition, only the HMW fraction is likely to contain arabino3,6-galactan moiety. This speculation was supported by the observation of a strong reactivity with the $\beta$-D-glucosyl-Yariv antigen, which reacts with arabinogalactan.

Reducing the risk of toxicity by therapeutics could be another important consideration during drug preparation. Although the LMW polysaccharide extracted from cloves has the less in vitro antithrombotic potency than the HMW fraction, it does not show the acute toxic effect in vivo. The anticoagulation action with no toxicity of LMW sulfated polysaccharide may represent a useful and safe antithrombotic agent. However, more extensive pre-clinical studies are needed to investigate its advantages over the HMW polysaccharide from cloves as well as other potential antithrombotics.

Acknowledgements This work was supported by grants from the agricultural R \& D promotion center of Korea.

\section{REFERENCES AND NOTES}

1) Bergé J. P., Bourgougnon N., Alban S., Pojer F., Billaudel S., Chermann J. C., Robert J. M., Franz G., Planta Med., 65, 604-609 (1999).

2) Hirsh J., Raschke R., Wakentin T., Dalen J. E., Deykin D., Poller L., Chest, 108, 258s-275s (1995).

3) Scully M. F., Ellis V., Kakkar V. V., Biochem. Biophys. Res. Commun., 41, 489-499 (1986).

4) Ofosu F. A., Choay J., Anvari N., Smith L. M., Blajchman L. M., Eur. J. Biochem., 193, 485-493 (1990).

5) Colliec S., Fischer A. M., Tapon-Bretaudiere J., Boisson C., Durand P., Jozefonvicz J., Thromb. Res., 64, 143-154 (1991).

6) Painter T. P., "The Polysaccharides," Vol. 2, ed. by Aspinall G. O., Academic Press, New York, 1982, pp.196-285.

7) Lee J. I., Lee H. S., Jun W. J., Yu K. W., Shin D. H., Hong B. S., Cho H. Y., Yang H. C., J. Korean Soc. Food Sci. Nutr., 29, 335-341 (2000).

8) Dubios M., Gilles K. A., Hamilton J. K., Rebers P. A., Smith F., Anal. Chem., 28, 350-356 (1956).

9) Blumenkronz N., Asboe-Hansen G., Anal. Biochem., 54, 484-489 (1973).

10) Lowry O. H., Rosebrough N. J., Farr A. L., Randoll R. J., J. Biol. Chem., 193, 256-275 (1951).

11) Dodgson K. S., Price R. G., Biochem. J., 84, 106-110 (1962). 
12) Yamada H., Kiyohara H., Cyong J. C., Kojima Y., Kumazawa Y., Otsuka Y., Planta Med., 50, 163-167 (1984).

13) Holst G. J., Clarke A. E., Anal. Biochem., 148, 446-450 (1985).

14) Jones T. M., Albersheim P. O., Plant Physiol., 49, 926-936 (1972).

15) Hakomori S., J. Biochem. (Tokyo), 55, 205-208 (1964).

16) Waeghe T. L., Darivill A. G., McNeil A. G., Albersheim P. O., Carbohydr. Res., 123, 281-304 (1983).

17) Nishino T., Kiyohara H., Yamada H., Nagumo T., Phytochemistry, 30, 535-539 (1991).

18) Hara T., Yokoyama A., Ishihara H., Yokoyama Y., Nagahara T., Iwamoto M., Thromb. Hemost., 71, 314-319 (1994).

19) Horton D., Renst K. J., Carbohydr. Res., 29, 173-179 (1973).

20) Lu R., Yoshida T., Nakashima H., Premanathan M., Aragaki R.,
Mimura T., Kaneko Y., Yamamoto N., Miyakoshi T., Uryu T., Carbohydr. Polym., 43, 47-54 (2000).

21) Pavão M. S. G., Aiello K. R. M., Werneck C. C., Silva L. C. F., Valente A. P., Mulloy B., Colwell N. S., Tollefsen D. M., Mourão P. A. S., J. Biol. Chem., 273, 27848-27857 (1998).

22) Hirsh J., Fuster V., Circulation, 83, 1449-1468 (1994).

23) Selvendran R. R, O’Neill M. A., Methods Biochem. Anal., 32, 153157 (1987).

24) Perlin A. S., Casu B., "The Polysaccharides," Vol. 1, ed. by Aspinall G. O., Academic Press, New York, 1982, pp. 133-192.

25) Nishono T., Takabe Y., Nagumo T., Carbohydr. Polym., 23, 165-173 (1994). 